\title{
An Investigation into Cooperative Learning in a Virtual World Using Problem-Based Learning
}

\author{
Vanessa Parson, \\ University of Sunderland \\ Simon Bignell, \\ University of Derby
}

\begin{abstract}
Three-dimensional multi-user virtual environments (MUVEs) have the potential to provide experiential learning qualitatively similar to that found in the real world. MUVEs offer a pedagogically-driven immersive learning opportunity for educationalists that is cost-effective and enjoyable. A family of digital virtual avatars was created within Second Life ${ }^{\circledR}$ to investigate the implementation of a problembased learning (PBL) task. The consensus among tertiary level educators was that the experience provided more immersion and engagement than traditional methods of technological provision, leading to potentially increased depth of learning. PBL appears to be an effective tool for aiding learning within immersive three-dimensional MUVEs.
\end{abstract}

Keywords: cooperative learning; problem-based learning, interactive learning environments; immersive learning; learning communities; teaching/learning strategies; virtual worlds; Second Life.

Parson, V. and Bignel, S. (2017). An investigation into cooperative learning in a virtual world using Problem-Based Learning. Online Learning 21:2. doi: 10.24059/olj.v21i2.796

\section{Introduction}

\section{Immersing Virtual Worlds in the Learning Experience}

Multi-user online virtual worlds (MUVEs) can provide an accessible and rapidly deployed platform for immersive learning and virtual research. These innovative virtual learning spaces are being used in many applications: gaming, social 
networking (Messinger, Stroulia, Lyons, Bone, Niu, Smirnov, \& Perelgut, 2009), marketing and commerce (Wasko, Teigland, Leidner, \& Jarvenpaa, 2011). One area where they hold the most potential is in technology-enhanced learning in education (Hinrichs \& Wankel, 2011, Bignell \& Parson, 2009, 2011). The immersive and cooperative learning communities that are possible in these structured virtual environments can engage learners in innovative and creative ways. The avatar at the centre of this experience, representing the user in the MUVE, gives control to the learner allowing the learner to interact virtually with educational content, enabling a synchronous learning experience outside of structured learning time (de Freitas, Rebolledo-Mendez, Liarokapis, Magoulas, \& Poulavassilis, 2010; Falloon, 2010; Gazzard, 2009; Johnson \& Levine, 2008).

Traditional two-dimensional (2D) virtual learning environments (VLEs) are just as effective at delivering many types of media to learners but MUVEs offer additional value in that they provide a heightened sense of inclusion to learners, in particular when they are away from educational premises (Bignell \& Parson, 2009, 2011). While traditional VLEs support asynchronous interactions, these interactions are less immersive and do not have the simulated physical interaction of a MUVE which contributes to the sense of involvement with the course and increases interaction with the material being learned. Educationalists, therapists and an increasing number of researchers are using avatars and groups to connect virtually with others. Just as the conventional 2D web has broken down barriers to the availability of information, three-dimensional (3D) virtual worlds, which thrive on user-generated content and learning communities, are allowing interactions between people irrespective of location, status or disability (Hinrichs \& Wankel, 2011).

These online virtual environments provide interactive and immersive experiences (Hinrichs \& Wankel, 2011; Johnson \& Levine, 2008; Bignell \& Parson, 2011) for cooperative group-based activities, providing an innovative approach that addresses critical thinking and problem-solving skills (Hrastinski, 2008). MUVEs hold the potential to provide authentic social and educational experiences within photo-realistic purpose-built environments: a seductive learning method for learners (Salmon, 2009), who are able to enhance the real-world application of their knowledge free from consequences inherent in the real world.

Virtual worlds have been used successfully as teaching resources in online role-player games (Aldrich, 2009; Childress \& Braswell, 2006; Hinrichs \& Wankel, 2011), medical education and training (Kamel-Boulos, Hetherington, \& Wheeler, 2007; Windsor, 2009), psychiatry education (Yellowlees, 2006) and more traditional e-learning courses (Hemmi, Bayne, \& Land, 2009). In medicine and psychiatry, students are able to practice techniques without the need for real patients, improving their skills without consequences for the mistakes that naturally occur during the learning process (Kamel-Boulos, et al., 2007, Windsor, 2009). In psychiatric models it is possible to demonstrate the experiences of those with mental health disorders and symptoms, such as hallucinations (Yellowlees, 2006), providing an enhanced understanding of the symptoms of future real-life patients. 


\section{Literature Review}

\section{Using Problem-Based Learning in Virtual Worlds}

It is well established that Problem-Based_Learning (PBL) leads to a deeper approach to learning (Newble \& Clarke, 1986) and there is ample evidence for the value of active and cooperative learning (Johnson, Johnson, \& Smith, 1991). Undergraduates require the ability to define problems, gather and evaluate information, and develop solutions so that they have the necessary skills to succeed in a work-based environment. PBL integrates these skills and combines them with critical and reflexive thinking skills (Poikela, 2004) The ability to use these skills to address problems in a complex real-world setting is one of the key enduring assets that undergraduates take with them beyond University. In PBL the emphasis is shifted from teaching to learning, encouraging individuals to think for themselves and explore new knowledge creatively (Esteves, Fonesca, Morgado, \& Martins, 2011). PBL traditionally involves alternating synchronous face-to-face discussions with asynchronous research; however, the basic premise of PBL is one that could easily transfer into a virtual setting. The interrelationship between technology and pedagogy, especially in relation to online PBL, requires considerable exploration (Savin-Baden \& Wilkie, 2006).

Experiential learning (Kolb, 1984), such as that utilized within PBL, is learning that occurs outside of formal learning establishments. There are no welldefined topics with sections of conveniently presented data as in traditional textbooks. Individuals search for information themselves, and then must integrate this information before it makes sense in relation to the initial problem posed. This is an effective method of learning, as it promotes self-directed learning, along with critical thinking and improved problem-solving skills.

A critical characteristic of learning in a MUVE is the idea that all learning is, in essence, experiential learning. This rewards the learner with a greater sense of ownership and control over his or her own knowledge and learning experiences (de Freitas \& Neumann, 2009; Johnson \& Levine, 2009; Kolb, 1984;). Experiential learning places experience and interaction at the heart of the learning process (SavinBaden, 2007; 2010); individuals encounter information in a non-sequential manner through their own interactions with their virtual environment. This method of learning focuses on the same skills as non-sequential learning: self-directed learning, critical thinking and problem-solving ability. Individuals also learn how to temper their responses to experiences in order to utilise all necessary knowledge to produce carefully weighed conclusions. MUVEs are an ideal forum for experiential learning as they are highly interactive with real-time task selection and exploration enabling enhanced self-directed learning and a sense of shared presence, which can contribute to lower levels of anxiety among students (Jarmon, Traphagan, Mayrath, \& Trivedi, 2009). The combination of PBL and online virtual worlds seems then to be an enticing mix for educators seeking to use online techniques that are both engaging and effective. 
There is a need to examine the efficacy of MUVEs to facilitate cooperative learning, specifically focusing on assessing support for the effectiveness of using PBL methods within MUVE's. It is well documented that MUVEs can be used within an educational situation, but there is limited evidence of their effectiveness in relation to traditional methods. It is important to look at how well MUVEs function as a learning tool when employing more traditional learning methods, so as to allow educators to view the potential in comparable, and familiar, formats.

It is hypothesised that the PBL scenarios will be viewed as an effective learning tool and that PBL itself will be viewed as an effective method for learning experiences within an MUVE (de Freitas \& Neumann, 2009, Author A \& Author B, 2011). It is expected that strengths and weaknesses of this learning method will be highlighted.

\section{Participants}

\section{Methods}

Nineteen participants, 10 male and 9 female, were selected through volunteer and opportunity sampling methods. Participants were individuals involved in education from university departments across the UK. The participants were spread across all academic disciplines, including learning support departments. Alongside this, specific institution-based focus group sessions were run at the author institutions. The mean age of participants was 43 years, 5 months. There was a range of technological capabilities, from complete MUVE beginners, to those familiar with advanced features of the software to ensure representation of all levels of technical ability. Students and educators have a diverse range of technical abilities and technology must be accessible to all individuals if used as a learning platform. A goal in this study was to have a range of technical ability rather than focus younger undergraduate students, which are only a sub-group of typical learners.

\section{Materials and Data Collection}

Second Life ${ }^{\circledR}$ (SL) was the MUVE chosen for this study. There are about 41 million accounts registered in Second Life ${ }^{\circledR}$ (Voyager, 2015). The starting point for the scenarios was a real-world problem that the learner must solve. In the problem-based scenarios, typical module content and learning outcomes were incorporated; in this way, learning was active, integrated with traditional course aims, cumulative, and connected with real world learning. A space comprised of virtual buildings and avatars was created (see Figure 1).

Figure 1: The virtual family house in Second Life ${ }^{\circledR}$. 


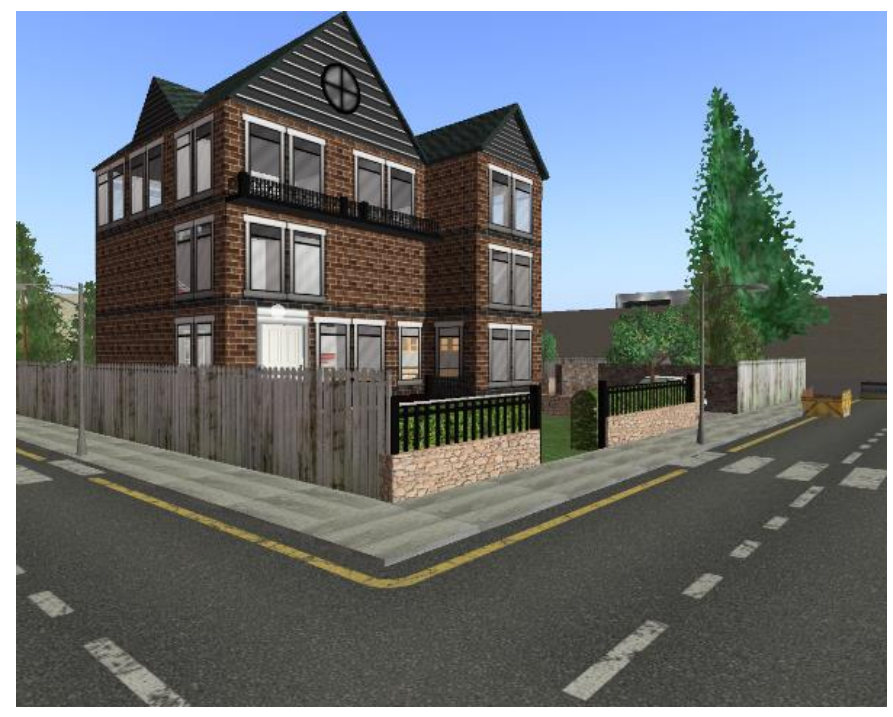

A virtual family was created within SL to explore and evaluate how this technology worked with the PBL method. A complex of virtual buildings was created, including a domestic residence, project office and information area (see Figure 1). Instructions, interactive note cards, posters, web links, and notice boards were provided within SL. The virtual house, information area, and virtual materials are accessible from within SL at this web-link: http://tinyurl.com/6zqhqxl. The questionnaire was designed to assess attitudes, opinions and views specific to the project (see Appendix 1).

Participants first went through inductions into SL before moving onto the PREVIEW-Psych project area. The participants worked in small groups using the problem statement (see Appendix 2) to establish whether the virtual child was safe within the existing family environment where multiple psychological and social issues were present (e.g. dementia, anorexia, alcoholism). A written response to the statement was required, using materials provided around the PBL area and within the house itself. Participants worked together to establish the virtual family dynamics, using the information provided within the PBL area, and the impact it had, along with collating basic information about these clinical disorders and the theoretical perspective in psychology which they considered most appropriate as a starting point for treatment.

Figure 2. The project information boards in the PREVIEW-PSYCH main area in Second Life ${ }^{\circledR}$.

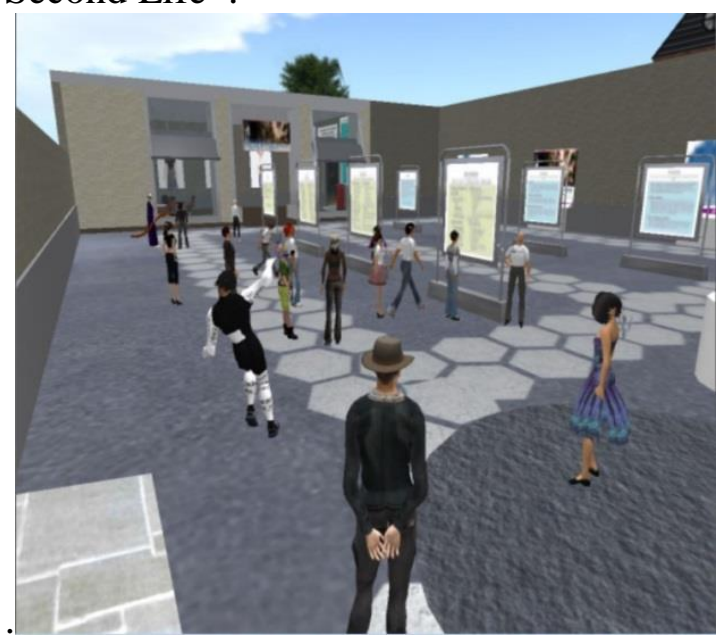


Before they began, participants had to allocate tasks to each individual group member. For example, some would look for information inside the virtual house (see Figure 1), some in the garden, and others on the information noticeboards (see Figure 2). A key element of the experience was to assimilate the information provided around the house and grounds, then come to a conclusion regarding the initial question posed (see Appendix 2). Within SL the participants entered the house and grounds twice as a small group of 4-6. They discussed their findings within world as a group and then produced a typed notecard, submitted via a virtual post-box to the experimenters. The institution-specific sessions were followed by hour-long focus groups in real life that included two groups of eight at University of Derby and one group of three at Aston University.

The virtual family of avatars and objects around the house were the source of much of the material. Participants were instructed to explore the virtual house and grounds using their avatar, when they approached a virtual family member or a designated object, they would be 'given' a notecard which contained either information about the character or a conversation between the avatars in the room. The information on the noticeboards in the main PBL area contained information about the basic issues affecting the virtual family (e.g. dementia, anorexia, alcoholism) and links to external websites containing more information about the issues presented.

\section{Results}

Data collected from the questionnaires was analysed quantitatively at a basic level to establish mean responses and qualitatively using thematic analysis $(n=19)$. Quantitative responses were generally around the midline with no significant deviations from this. Generally, participants found SL easy and straightforward to use (see Table 1), the instructions were clear, and help was not needed often.

Table 1. Educator self-report evaluations of PBL use in Second Life ${ }^{\circledR}$.

\begin{tabular}{lll}
\hline Using PBL within SL & Mean & $\begin{array}{l}\text { Standard } \\
\text { Deviation }\end{array}$ \\
\hline $\begin{array}{l}\text { How easy was it to move around } \\
\text { Second Life? }\end{array}$ & 3.58 & 2.22 \\
\hline $\begin{array}{l}\text { How straightforward was it to work } \\
\text { out what to do? }\end{array}$ & 4.26 & 1.88 \\
\hline $\begin{array}{l}\text { How often did you require help on a } \\
\text { scale of 1-10? }\end{array}$ & 5.30 & 2.45 \\
\hline How clear were the instructions? & 3.58 & 2.04 \\
\hline $\begin{array}{l}\text { How easy was it to use the materials } \\
\text { that were available to you in SL? }\end{array}$ & 4.47 & 2.15 \\
\hline $\begin{array}{l}\text { How difficult was it to find material in } \\
\text { SL on a scale of 1-10? }\end{array}$ & 4.13 & 1.78 \\
\hline $\begin{array}{l}\text { How easy was it to access the material } \\
\text { provided in SL? }\end{array}$ & 3.79 & 1.69 \\
\hline $\begin{array}{l}\text { How easy was it to communicate with } \\
\text { other individuals in SL? }\end{array}$ & 3.65 & 1.87 \\
\hline
\end{tabular}


Scores based on 1 being an extremely positive score and 10 being an extremely negative score.

The resources within SL were largely seen as useful. The most popular resources were notecards (76\%), web links $(62 \%)$ and the interactive whiteboard (62\%). Most participants $(76 \%)$ used the general text chat rather than real-world conversation $(19 \%)$ and private text chat $(19 \%)$.

Using thematic analysis (Braun \& Clarke, 2006, 2013) a series of four themes were identified from the feedback on the qualitative questions from the questionnaire given to the educators' post-MUVE experience: potential, technical issues, immersion, and pedagogy. The data was organised in relation to these themes and quantified in relation to the themes (see Figure 3).

The clearest theme that emerged was the potential PBL within a MUVE had for learning. The participants involved felt that while there was potential it was not ready as an educational tool and evidence of effectiveness as an educational resource was needed before including it in courses.

The second theme to emerge was that relating to technical issues. Participants thought that technical difficulties could interfere with the learning experience and felt that if technical issues could be overcome the potential for PBL within MUVEs to be used as a learning tool would be increased. Some participants had problems using SL itself, although these were mainly technical unfamiliarity issues and orienting to the graphical user interface. Problems that arose during the use of the PBL method comprised of technical issues within SL itself rather than problems relating to PBL; having a technician present to assist was invaluable to the smooth running of the actual teaching session. A concern arose that the learning curve of SL itself was timeconsuming, specifically for less technologically capable individuals; yet once these issues were overcome, the potential was clearly communicated.

The third theme of immersion showed that participants found the experience of using SL was a highly immersive, straightforward and entertaining tool for learning. Within this theme, participants highlighted the distraction element of immersion. Participants felt that some students would get distracted purely due to immersion, being side-tracked by exploring the MUVE and forgetting about task requirements. Immersion itself, such a useful tool in learning, could potentially affect individuals achieving specific learning goals.

Figure 3. Thematic analysis data presented as percentages of total responses. 

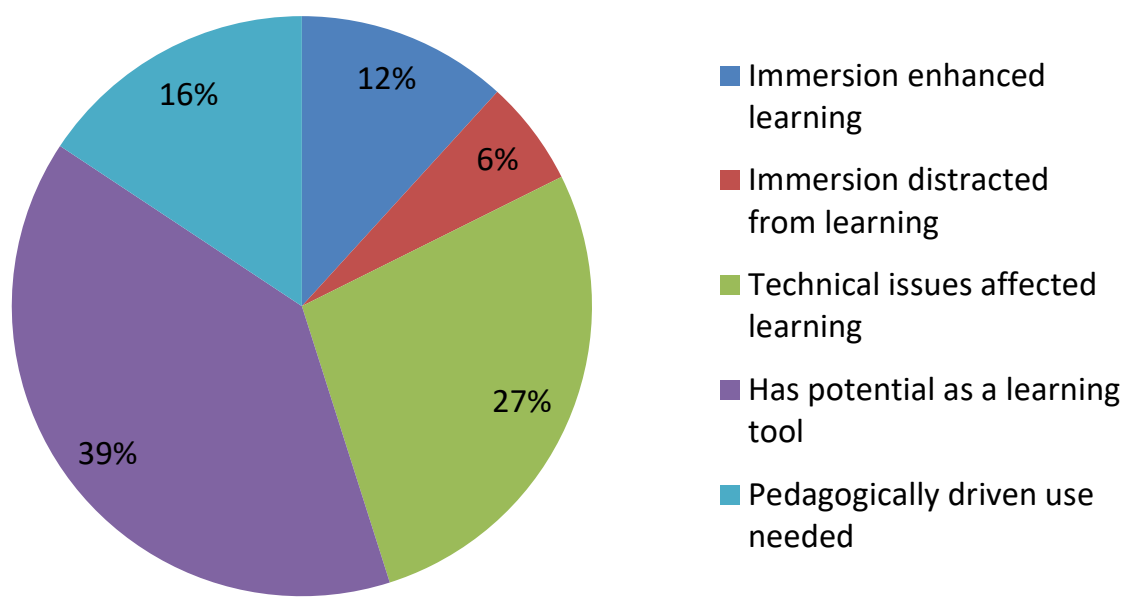

Finally, the theme of pedagogy arose. Participants felt that using MUVEs within educational settings should be pedagogically driven. Given the immersive nature of SL and the potential time required to learn fully how to use it, whimsical use to make a course more appealing was seen as poor practice. Participants suggested a sound purpose-driven approach for inclusion of MUVEs in courses. It was specifically suggested that immersive nature of MUVEs was more suited to distance learning courses since the immersion element filled a niche that was inherently absent within such courses.

\section{Discussion}

Using PBL within a MUVE showed potential, from an educator perspective. The experience was immersive, straightforward and engaging, with educators perceiving this learning tool as having potential, in particular for distance learning courses. While educators did acknowledge the potential for using PBL in MUVEs, they also highlighted some concerns. Technical issues did interfere with the task, and the MUVE orientation was time-consuming. The consensus was that this was not a whimsical addition to a course, and inclusion should serve a clear pedagogical purpose.

A unique element of this study was that it involved educators with a range of technical ability from several different institutions working together in virtual PBL scenarios rather than focusing on undergraduate students. The results support numerous studies which show educators' opinion regarding the use of MUVEs for learning to be generally very positive (Childress \& Braswell, 2006; de Freitas, et al., 2010; KamelBoulos, et al., 2007; Hemmi, et al., 2009; Hobbs, et al., 2006).

As the educators in our study perceived, MUVEs have the potential to enhance greatly the learning experience for individuals. There is evidence that individuals who have taken part in experiential learning in MUVEs have continued with their projects after the formal learning has finished (Childress \& Braswell, 2006; Jarmon, et al., 2009), individuals appear so immersed in the learning experience that removal from the project does not occur and learning continues long after the formal learning situations have ended. This was indeed the case with our sample, several participants requested further support in setting-up their own MUVEs or were leant virtual project space to develop and test educational uses. 
The clear potential of the PBL method itself within MUVEs was strongly identified in our cohort of educators, and this is encouraging: MUVEs offer opportunities for individuals to engage with synchronous and asynchronous immersive learning (Savin-Baden \& Wilkie, 2006). As a persistent 3D learning environment the content placed in-world by educators remains there for learners to access in their own time or to use as part of live teaching sessions. As a tool for online distance learning MUVEs offer an immersive experience not traditionally experienced by those engaged in distance learning courses (de Freitas, et al., 2010). Learning in collaboration with peers allows individuals to feel more integrated and in-touch with others on the course; leading to lowered attrition rates (de Freitas, et al., 2010; Falloon, 2010) and an associated feeling of achievement while learning and a sense of ownership of learning.

MUVEs hold the potential to enhance the learner experiences (de Freitas \& Neumann, 2009): providing them with an interactive and immersive information paradigm that could encourage independent learning; increasing interaction and use of course material. This was clearly identified by our participants, and they responded favourably to the high level of engagement that PBL within an MUVE afforded. Integrating use of MUVEs into educational paradigms allows educators to hand over ownership of learning to the learners rather than relying on a transfer of information teaching paradigm (Falloon, 2010; Mayrath, et al., 2010). Using MUVEs as a learning tool is likely to be most effective when facilitating individuals to take ownership of their learning and engage in truly cooperative teaching sessions (Johnson, et al., 1991, Hrastinski, 2008, Hinrichs \& Wankel, 2011, Author A \& Author B, 2011).

While the use of MUVEs in teaching has potential, there were clear concerns from our participants about the technological capabilities of institutions and within MUVEs themselves, which have been highlighted previously by other educators and researchers (de Freitas, et al., 2010; Salmon, 2009). There is clearly a delicate balance to be achieved between the technical aspects and the fluency of a virtual worlds teaching session. MUVEs such as SL, require a large amount of server capacity and a relatively high specification of computer to run effectively, and are not always intuitive to use and communication can be hindered simply through a lack of knowledge about basic technical elements (Jarmon, et al., 2009). However, although orientation can be time consuming and moving within a MUVE may not be intuitive to many initially, it does not take long before one is competent in moving around and communicating easily (Jarmon, et al., 2009) and this did not dissuade our educators from perceiving the potential of this technology. Our participants were clear that technological concerns were the primary factor that would influence their decisions to include MUVEs on their courses.

The current study looked at educator perceptions, which are a key first step in providing an enhanced learning experience for students; their experiences are of value in appraising the validity of such methods. Clearly there is a need for student opinions to support educator viewpoints and students must be willing to engage with MUVEs for them to be effective, and so they must perceive the benefits to them. Future studies will focus on student feedback, as this will encourage educational practitioners to consider investing in using MUVEs. 
Caution must be exercised in generalizing from the findings of the current study due to the modest sample size and the reliance on a single academic subject. Likewise, the lack of a comparison control group places some limitations on the direct comparability to traditional classroom-based PBL methods.

Well-designed MUVE learning experiences can potentially enhance the learning journey of the individuals using the program (Salmon, 2009). Use of virtual worlds in education could provide additive benefits to individuals' learning and provide a highly useful tool. To date studies directly investigating outcomes when individuals learn in MUVEs and real-life have found no significant differences in performance outcomes (Okutsu, Delaurentis, Brophy, \& Lambert, 2013), indicating that learning in a MUVE is comparable to learning in real-life; a finding that may have considerable implications for designers of both campus-based and distance learning educational programmes. The next stage of the current project is to investigate the pedagogical outcomes from this PBL task, comparing student performance within real world and MUVEs directly and assessing using identical, and robust, traditional methods that are pervasive throughout the education system. This will provide a set of results by which a direct comparison of traditional PBL and PBL within an MUVE can be achieved, and the value of MUVE inclusion on courses can be assessed objectively in line with typical practice.

\section{Recommendations}

Many further and higher education institutions are considering the development and expansion of online education as part of their planning activities (Picciano, 2015). To prevent the possible pitfalls of implementation, adequate technology planning that allows academics and technicians to work together in the development of PBL virtual scenarios is necessary. In the development of original materials for virtual world PBL sessions, well-designed problems which can be visualized in realistic scenarios are essential and educators and technical developers need to work together in the creation of these.

Although virtual worlds and gamification enable authentic learning and role play (Wills, Leigh, \& Ip, 2011; Childs \& Peachey, 2011; Childs \& Peachey, 2013), these innovative methods rely on several factors for their success. Virtual worlds, just like video games, excel at engagement and immersion (McGonigal, 2011). However, students and educators alike need a point and academic purpose to each PBL activity to engage learners in immersive creative problem solving scenarios. This is challenging to design into many academic programmes and developers will require adequate time and sufficient technical backup if these methods are to succeed.

Before venturing into the development and building phase of immersive virtual educational scenarios educators must be certain of their goals. For the investment in time and resources to be worth it, educators must be clear on specific learning outcomes, pedagogy and commitment from both staff and students. One way to do this is through the piloting of virtual PBL teaching materials and sufficient tutoring of all those involved with delivery. If the pedagogical, immersion and technical matters are realised the argument for using powerful subject-driven problem-based learning scenarios is persuasive. 
The purpose of this study was to explore cooperative learning in a group of educators of different technical abilities from different institutions. The findings were consistent with much of what is known about teaching and learning in immersive online environments; that using PBL within MUVEs is a potentially engaging addition to educational practice and that while technological issues exist, they are thought by educators not to be insurmountable. MUVEs are immersive and have the potential to facilitate learning; the focus is on facilitating experiential learning rather than directed teaching. Use of MUVEs is perceived as most effective where there is a sound pedagogical purpose and where learning is facilitated and scaffolded initially by the educator.

\section{References}

Aldrich, C. (2009). Learning online with games, simulations, and virtual worlds: Strategies for online instruction (Vol. 23). Jossey-Bass.

Bignell, S. \& Parson, V.. (2009). Best Practices in Virtual Worlds Teaching: A guide to using problem-based learning in Second Life (PREVIEW-Psych project guide) http://previewpsych.org/?p=200

Bignell, S. \& Parson, V. (2011). Case Study 5: Moving into virtual worlds, JISC: HEFCE, retrieved from http://www.jisc.ac.uk/media/documents/programmes/elearning/digiemerge/ 5_JISC_EmPDA_Derby.pdf

Braun, V., \& Clarke, V. (2013). Successful qualitative research: A practical guide for beginners. London: Sage.

Braun, V., \& Clarke, V. (2006). Using thematic analysis in psychology. Qualitative Research in Psychology, 3(2), 77-101.

Childress, M.D., \& Braswell, R. (2006). Using Massively Multiplayer Online Role Playing Games for Online Learning. Distance Education, 27(2), 187-196. DOI: $10.1080 / 01587910600789522$

Childs, M., \& Peachey A. (2011). Reinventing ourselves: contemporary concepts of identity in Virtual Worlds. New York, Springer.

Childs, M., \& Peachey A. (2013). Understanding Learning in Virtual Worlds. London, Springer.

de Freitas, S. D., \& Neumann, T. (2009). The use of 'exploratory learning 'for supporting immersive learning in virtual environments. Computers \& Education, 52(2), 343-352.DOI: 10.1016/j.compedu.2008.09.010

de Freitas, S., Rebolledo-Mendez, G., Liarokapis, F., Magoulas, G., \& Poulavassilis, A. (2010). Learning as immersive experiences: using the fourdimensional framework for designing and evaluating immersive learning experiences in a virtual world. British Journal of Educational Technology, 41(1), 69-85. DOI: 10.1111/j.1467-8535.2009.01024.x 
Esteves, M., Fonesca, B., Morgado, L., \& Martins, P. (2011). Improving teaching and learning opf computer programming thought the use of the Second Life virtual world. British Journal of Educational Technology, 42(4), 624-637.

Falloon, G. (2010). Using avatars and virtual environments in learning: what do they have to offer?. British Journal of Educational Technology. 41(1), 108122. DOI: 10.1111/j.1467-8535.2009.00991.x

Gazzard, A. (2009). The avatar and the player: understanding the relationship beyond the screen. In G. Rebolledo-Mendez, F. Liarokapis \& S. de Freitas (Eds), Proceedings of the IEEE Games and Virtual Worlds for Serious Applications conference, Coventry, UK (pp. 190-193). Proceedings of the 1st IEEE International Conference in Games and Virtual Worlds for Serious Applications, IEEE Computer Society, Coventry, UK, 23-24 March. DOI: 10.1109/VS-GAMES.2009.11

Hemmi, A., Bayne, S., \& Land, R. (2009). The appropriating and repurposing of social technologies in higher education. Journal of Computer Assisted Learning, 25(1), 19-30. DOI: 10.1111/j.1365-2729.2008.00306.x

Hinrichs, R., \& Wankel, C. (Eds). (2011). 3D Virtual World Learning Handbook, Bingley, UK: Emerald Publishing

Hobbs, M., Brown, E., \& Gordon, M. (2006). Using a virtual world for transferable skills in gaming education. Innovation in teaching and learning in information and computer sciences, 5(3), 42-55. DOI: 10.11120/ital.2006.05030006

Hrastinski, S. (2008). Asynchronous \& Synchronous E-Learning, Eduserv Quarterly, 4, 51-55.

Jarmon, L., Traphagan, T., Mayrath, M., \& Trivedi, A. (2009). Virtual Teaching, experiential learning and assessment: an inter-disciplinary communication course via Second Life, Computers and Education, 53: 169-182.

Johnson, D. W., Johnson, R. T., \& Smith, K. A. (1991). Cooperative Learning: Increasing College Faculty Instructional Productivity. ASHE-FRIC Higher Education Report No.4. Washington, D.C.: School of Education and Human Development, George Washington University.

Johnson, L.F., \& Levine, A.H. (2008). Virtual worlds: inherently immersive, highly social learning spaces. Theory into Practice, 47, 161-170. DOI: 10.1080/00405840801992397

Kamel-Boulos, M.N., Hetherington, L., \& Wheeler, S. (2007). Second Life: an overview of the potential of 3-D virtual worlds in medical and health education. Health Information and Libraries Journal, 24, 233-245.

Kolb, D.A. (1984). Experiential learning: experience as the source of learning and 
development. Englewood Cliffs: NJ. Prentice-Hall.

Mayrath, M.C., Traphagan, T., Jarmon, L., Trivedi, A., \& Resta, P. (2010). Teaching in virtual worlds: factors to consider for instructional use of Second Life, Journal of Educational Computing Research, 43(4): 403-444. DOI: $10.2190 /$ EC.43.4.a

McGonigal, J. (2011). Reality Is Broken: Why Games Make Us Better and How They Can Change the World. Penguin Press. New York, NY.

Messinger, P. R., Stroulia, E., Lyons, K., Bone, M., Niu, R. H., Smirnov, K., \& Perelgut, S. (2009). Virtual worlds—past, present, and future: New directions in social computing. Decision Support Systems, 47(3), 204-228.

Newble, D. I., \& Clarke, R. M. (1986). The approaches to learning of students in a traditional and in an innovative problem-based medical school. Medical Education, 22, 26-273. DOI: 10.1111/j.1365-2923.1986.tb01365.x

Okutsu, M., Delaurentis, D., Brophy, S., \& Lambert, J. (2013). Teaching in an aerospace engineering design course via virtual worlds: a comparative assessment of learning outcomes, Computers and Education, 60:288-298. DOI: 10.1016/j.compedu.2012.07.012

Author A., \& Author B. (2011). Using problem-based learning within 3D virtual worlds, in Hinrichs, R. and Wankel, C. (Eds.), Transforming Virtual World Learning: Cutting-edge technologies in higher education, Vol. 4, pp. 245265. Emerald Group Publishing Limited: Teynampet, India.

Picciano, A.G. (2015). Planning for Online Education: A Systems Model. Online Learning Journal, 19(5).

Poikela, E. (2004). Developing criteria for knowing and learning at work: towards context-based assessment. Journal of Workplace Learning, 16(5), 267-274.

Salmon, G. (2009). The future for (second) life and learning. British Journal of Educational Technology. 40(3), 526-538. DOI: 10.1111/j.14678535.2009.00967.x

Savin-Baden, M. (2007). A Practical Guide to Problem-based Learning Online. London: Routledge.

Savin-Baden, M. (2010). A Practical Guide to using Second Life in Higher Education. Maidenhead: McGraw Hill.

Savin-Baden, M., \& Wilkie, K. (Eds.). (2006). Problem-based learning online. Open University Press.

Voyager, D. (2015). Second Life Metrics [Web log post]. Retrieved from http://danielvoyager.wordpress.com/sl-metrics/ 
Wasko, M., Teigland, R., Leidner, D., \& Jarvenpaa, S. (2011). Stepping into the internet: New ventures in virtual worlds. MIS Quarterly, 35(3), 645-652.

Wills, S., Leigh, E., \& Ip, A. (2011). The Power of Role-based e-learning: Designing and moderating online role play. London, Routledge.

Windsor, J.A. (2009). Role of simulation in surgical education and training. ANZ Journal of Surgery, 79, 127-132. DOI: 10.1111/j.1445-2197.2008.04829.x

Yellowlees, P.M. (2006). Education about Hallucinations Using an Internet Virtual Reality System: A Qualitative Survey. Academic Psychiatry, 30(6), 534539. DOI: 10.1176/appi.ap.30.6.534 


\section{Appendix 1}

\section{Example Questions}

1. Did you encounter any problems with orienting and moving in SL? 1 (very often) 23455678910 (not at all)

2. How easy was it to access the material provided in SL? 1 (very easy) 23445678910 (very difficult)

3. How clear were the instructions? 1 (very clear) $2 \quad 3 \quad 4 \quad 56788910$ (not clear at all - I had no idea what I was doing!)

4. How easy was it to communicate with other individuals in SL? 1 (very easy) 23456678910 (very difficult)

5. How easy did you find it to ask other avatars for information? 1 (very easy) $2 \quad 3 \quad 4 \quad 56788910$ (very difficult)

6. How straightforward was it to gather information? 1 (very easy) $2 \quad 3445678910$ (very difficult)

7. How often did you require help on a scale of 1-10? 1 (very often) $2 \quad 3 \quad 4 \quad 567789910$ (not at all)

8 . Were you successful in solving the problem set?

9. How useful do you think SL is as a tool for education? 


\section{PBL Initial Problem Statement}

\section{Appendix 2}

Problem-Based Learning in a Virtual World Scenario Sheet: Approaches in Psychology

There are various approaches in psychology for studying how people interact and function in their daily lives. These approaches allow us to interpret disorders; enabling specific treatment for any individuals who may not be able to function without help. Some common problems which people experience are easily treatable and enable them to have a normal life. Some problems are more difficult and require more extensive treatment, possibly preventing individuals from living life without support and preventing them from caring for others.

Social workers and Psychologists routinely have to evaluate families to assess normality of functioning. They have to look at what might be wrong with each family member and whether this treatment appears to be effective at helping them to lead a normal life. However, the most effective way is usually through observation rather than asking questions. Something many Social Workers and Psychologists would like to have is a view of how a family functions on a daily basis. This option is provided in Second Life, in a house containing a virtual family. This family is in need of assessment and all are currently being treated for some form of disorder.

As far as social workers are concerned families which are not able to care for a child, should receive additional help to care for their child. As a Psychologist you know that the best option for the child is to be cared for by their own family, and give them help should they need it, rather than taking a child into care. Whether you can manage a disorder depends on the approach taken to treat it, and the success of that treatment in the long term. 